\title{
Lexical-semantic processing in the semantic priming paradigm in aphasic patients
}

\author{
Processamento léxico-semântico no paradigma de priming semântico em pacientes afásicos \\ Jerusa Fumagalli de Salles', Candice Steffen Holderbaum², Maria Alice Mattos Pimenta Parente ${ }^{3}$, Letícia \\ Lessa Mansur ${ }^{4}$, Ana Inès Ansaldo 5
}

\begin{abstract}
There is evidence that the explicit lexical-semantic processing deficits which characterize aphasia may be observed in the absence of implicit semantic impairment. The aim of this article was to critically review the international literature on lexical-semantic processing in aphasia, as tested through the semantic priming paradigm. Specifically, this review focused on aphasia and lexical-semantic processing, the methodological strengths and weaknesses of the semantic paradigms used, and recent evidence from neuroimaging studies on lexical-semantic processing. Furthermore, evidence on dissociations between implicit and explicit lexical-semantic processing reported in the literature will be discussed and interpreted by referring to functional neuroimaging evidence from healthy populations. There is evidence that semantic priming effects can be found both in fluent and in non-fluent aphasias, and that these effects are related to an extensive network which includes the temporal lobe, the pre-frontal cortex, the left frontal gyrus, the left temporal gyrus and the cingulated cortex.
\end{abstract}

Key words: aphasias, mental processes, language, stroke.

RESUMO

Há evidências de que os déficits de processamento léxico-semântico explícitos que caracterizam a afasia podem ser observados na ausência de déficits semânticos implícitos. O objetivo deste artigo foi analisar criticamente a literatura internacional sobre processamento léxico-semântico na afasia, avaliado por meio do paradigma de priming semântico. Especificamente, esta revisão teve seu foco na afasia e processamento léxico-semântico, pontos fortes e fracos da metodologia dos paradigmas léxico-semânticos usados, e evidências recentes de estudos de neuroimagem sobre o processamento léxico-semântico. Além disso, evidências de dissociações entre processamento léxico-semântico implícito e explícito relatadas na literatura serão discutidas e interpretadas, relacionando-se aos dados de neuroimagem funcional de amostras saudáveis. Há indícios de que os efeitos de priming semântico podem ser encontrados tanto em afasias fluentes como em não fluentes, e que esses efeitos são relacionados a uma extensa rede que inclui o lobo temporal, o córtex pré-frontal, o giro frontal esquerdo, o giro temporal esquerdo e o córtex cingulado.

Palavras-Chave: afasias, processos mentais, linguagem, acidente vascular cerebral.

\section{APHASIA AND APHASIA TYPES}

Aphasia is defined as the loss of or deficiency in expressive and/or receptive language, and is generally caused by a left hemisphere lesion, such as a stroke. Aphasias are a frequent source of neuropsycholinguistic (or cognitive-linguistic) impairment, and represent the most disabling of stroke conditions, interfering with communicative, social and work abilities, as well as (re)integration into society. Most aphasic patients have deficits in more than one cognitive process ${ }^{1}$. There are various approaches classifying aphasias. Combining anatomical and linguistic classifications, the classic division proposes two large groups: (1) the anterior Broca's aphasias (or "non-fluent"), and (2) the posterior Wernicke's aphasias (or "fluent"). Considering the anatomical location of the brain damage, they may also be called pre-rolandic and post-rolandic ${ }^{2}$.

\footnotetext{
${ }^{1}$ Professor of the Department of Developmental and Personality Psychology, Graduate Studies Program in Psychology, Institute of Psychology, Universidade Federal do Rio Grande do Sul (UFRGS), Porto Alegre RS, Brazil;

${ }^{2}$ Doctorate student of the Graduate Studies Program in Psychology, Institute of Psychology, UFRGS, Porto Alegre RS, Brazil;

${ }^{3}$ Prof. Dr. of Department of Developmental and Personality Psychology, Institute of Psychology, Graduate Studies Program in Psychology, UFRGS, Porto Alegre RS, Brazil; ${ }^{4}$ Professor associated of Speech Therapy Course of the Department of Physical Therapy, Speech Therapy and Occupational Therapy of the School of Medicine at the Universidade de São Paulo (USP), São Paulo SP, Brazil;
}

${ }^{5}$ Laboratoire de Plasticité Cérébrale, communication et vieillissement (LPCV), Centre de Recherche de l'Institut Universitaire de Gériatrie de Montréal, University of Montréal, Montreal, Quebec, Canada.

Correspondence: Jerusa Fumagalli de Salles; Avenida Ramiro Barcelos 2600/114; 90035-003 Porto Alegre RS - Brasil; E-mail: jerusafs@yahoo.com.br

Conflict of interest: There is no conflict of interest to declare.

Received 06 February 2012; Received in final form 23 February 2012; Accepted 05 March 2012 
Recently, Ardila ${ }^{3}$ proposed a new aphasia classification, emphasing that there are two fundamental forms of aphasia: one characterized by impairments in lexical/semantic systems of language (Wernicke-type aphasia) and the other characterized by impairments in grammatical systems of language (Brocatype aphasia). These are called primary language disturbances or central aphasias. In addition, the author demonstrated that lexical/semantic and grammatical systems depend on different types of memory and learning (declarative and procedural).

Broca's aphasia is characterized by impaired spontaneous speech, repetition of sentences, reduced phrase length, prosody, deficient articulatory programming, fewer words spoken per minute, production of agrammatical sentences and word-finding deficits (anomia), as well as a greater difficulty in naming verbs than nouns. These difficulties cannot be explained by a single underlying deficit ${ }^{1}$. Additionally, phoneme-grapheme association deficits can affect reading and writing. These features are observed in the context of relatively well-preserved language comprehension abilities. People with Broca's aphasias, despite having more pronounced language-expression deficits, also exhibit difficulties with sentence comprehension, which have been related to lexical-semantic processing deficits ${ }^{4}$.

Wernicke's aphasia is characterized by fluent senseless production (jargon) with no articulatory effort, as well as impaired word, sentence and discourse comprehension. In contrast with Broca's aphasia, people with Wernicke's aphasia are generally not aware of their language impairment (anosognosia). Written language presents a similar profile to that of oral language, both at the receptive and production levels. Wernicke's aphasia is considered to be a result of deficient lexical control, which prevents a person from selecting the appropriate word, sound or meaning within a competing context of concurrent activation ${ }^{1}$. In Wernicke's aphasias, comprehension impairments reflect more the inability to access, use or manipulate semantic information than a loss of the semantic representations of the words ${ }^{5}$.

A distinctive feature of aphasia is anomia - a wordfinding impairment which is the most frequent clinical sign across all aphasia types - . Two types of anomia have been described: (a) phonological anomia and (b) semantic anomia. Phonological anomia results from impaired access to the target's phonological information, and intact access to the corresponding semantic representations. It may give raise to phonological or semantic paraphasia; patients with phonological anomia are aware of the fact that the errors they produce are semantically or phonologically related to the target ${ }^{1}$. Regarding semantic anomia, it is characterized by impaired semantic processing resulting in semantic errors (e.g.: dogcat) at the comprehension and production levels and preserved repetition abilities ${ }^{1}$. Semantic errors can be the expression from many types of semantic processing problem: modality and category-specific impairments or input and output semantic impairments ${ }^{6}$. The possibility of using semantic knowledge will depend on the type and level of impairment. Both fluent and non-fluent aphasias present a certain degree of impaired explicit lexical-semantic processing, as measured by specific tasks; conversely, they may show preserved implicit semantic abilities, as evidenced by indirect assessment tasks, such as the semantic priming paradigm.

The purpose of this paper was to critically review the literature on implicit lexical-semantic processing, in particular by referencing the results obtained with the semantic priming paradigm. Focus will be placed on fluent and non-fluent aphasias. Methodological issues regarding the semantic priming paradigm will be discussed and examined across aphasia subtypes, in particular by referencing the dissociations between explicit and implicit lexical-semantic processing (semantic priming effect) observed in these populations. Furthermore, the neural correlates of implicit semantic processing as assessed by semantic priming paradigms will be discussed.

\section{LEXICAL-SEMANTIC PROCESSING}

Lexical-semantic processing encompasses access to the lexicon and to the semantic system. Lexical processing includes a set of processes through which the listener or reader recognizes word forms (orthographic and phonological), perceives and understands their meaning, and accesses other target properties stored in his mental dictionary or mental lexi$\mathrm{con}^{7}$. The mental lexicon stores word-related knowledge as word sound, spelling and grammatical properties (word class, gender), as well as morphological structure and meaning ${ }^{8}$.

According to cascade models, word recognition (comprehension) involves not only simultaneous bottom-up sensorial information from the target word but also top-down contextual information represented by the listener/reader's expectations, context, memory and attention. Thus, lexical knowledge comprises the representational domains of word form and meaning ${ }^{8}$. In parallel, distributed processing or connectionist models, target-related information, whether phonological or semantic, is represented in terms of distributed patterns of activity in distinct groups of processing units, similar to neurons ${ }^{9,10}$.

The semantic and lexical systems are functionally independent ${ }^{11,12}$ - each word has a phonological/orthographic representation and a semantic one $\mathrm{s}^{13}$ - as evidenced by errors in oral naming, combined with intact word comprehension. Errorless performance on oral and written comprehension tasks indicates intact semantic word representations. Therefore, there are patients who present difficulties in oral and written naming tasks, along with normal performance in language comprehension tasks. In addition, there is evidence of the opposite dissociation: an intact access to word forms (phonology) along with impaired access to semantic representations ${ }^{12}$. 
The importance of word meaning in the processing of words is undeniable ${ }^{8}$. Semantic representations comprise a number of semantic features (visual, sensory and functional, among others) that define the meaning of a word ${ }^{11}$. According to McClelland and Rogers ${ }^{14}$, semantics involves spreading activation between simple processing units (nodes), similar to neurons, and their connections. Experience models the strength or weight of these connections and determines the degree of representation (strong versus weak) of a particular lexical item. This is one of the most commonly used theories to explain the results of the semantic priming effect $(\mathrm{SPE})^{15}$.

\section{THE SEMANTIC PRIMING PARADIGM}

Priming effects concern implicit, unconscious memory abilities of past experiences, which have an indirect influence on future behavior ${ }^{16}$. The assessment of such effects is done by means of indirect tests, that is, those which involve motor or cognitive activities related to a learning event, but in which the instructions do not directly refer to that. Implicit memory is generally disregarded in most neuropsychological assessment batteries ${ }^{17,18}$ and has proven to be an intervention resource in people with explicit memory ${ }^{19}$ and communication deficits ${ }^{20}$.

Semantic priming paradigms specifically examine priming effects on lexical stimuli, particularly by examining the role of semantic context in word recognition (top-down processing). In semantic priming paradigms, the target presentation is preceded by a prime - a word that can provide a semantic context and for which no response is required - Primes can be words or non-words. In lexical decision tasks, the presentation of the prime is followed by a target, a string of letters which may or may not correspond to a word. Participants are asked to decide whether the stimulus is a real word or not, either by providing an oral or a motor response.

The priming effect corresponds to the difference in speed or accuracy between responses to target words preceded by related primes and those preceded by unrelated or neutral primes (e.g. non-linguistic stimuli). In studies that add a neutral prime context and use it as baseline, the resulting difference is called facilitation (when reaction time to the related condition is shorter) or inhibition (when reaction time to the related condition is longer) ${ }^{15}$.

Several theories have been proposed to explain the semantic priming effects found so far. According to Neely ${ }^{15}$, none of these theories provides an explanation for all the existing data and probably no new theory would be able to do so ( for more details see McNamara ${ }^{21}$ ). Among these theories, some consider semantic priming to be an automatic process (i.e. "spreading activation" theories) and others consider it to be a result of expectancy (i.e. "expectancy-induced” theories). This is one the most commonly used theories to explain the results of the semantic priming effect (SPE).
In a given experiment, the main factor used to modulate automatic versus controlled priming is the stimulus onset asynchrony (SOA). SOA represents the interval between the onset of the prime presentation and the beginning of the target. It is considered that short SOAs (smaller than $300 \mathrm{~ms}$ ) is mainly due to automatic processes, whereas a long SOAs (longer than $300 \mathrm{~ms}$ ) will cause semantic priming effects trigger specially by controlled processes. Although until recently SPE was considered to be driven by automatic processes with SOAs smaller than $300 \mathrm{~ms}$, in the last few years evidence has suggested that it should preferably be less than $150 \mathrm{~ms}$ to rely on the automatic process ${ }^{22}$. Still, there is evidence that, even with a short SOA, a certain degree of controlled processing may be involved ${ }^{15}$. Thus, spreading activation and strategic processes are not totally independent; rather, the contribution of the former mechanism is greater for short SOAs.

\section{NEURAL CORRELATES OF LEXICAL-SEMANTIC PROCESSING AND THE SEMANTIC PRIMING EFFECTS}

From a neurofunctional perspective, it is widely accepted that the neural basis of semantic knowledge is extensively distributed in the brain; the evidence comes from neuroimaging studies with healthy participants ${ }^{23-25}$ and also from studies with brain-damaged patients with semantic defi$\mathrm{cits}^{14}$. In a fMRI study, Hauk, Davis, Kherif and Pulvermüller ${ }^{23}$ examined the brain activation patterns of words with different semantic associations during a silent reading paradigm in a group of healthy subjects. They concluded ${ }^{23}$ that actionrelated words significantly activate action-processing brain areas, as the left-middle temporal gyrus, whereas words allowing for visual imagery significantly activate visual-processing areas, specifically the left fusiform gyrus.

The processing of words (lexical-semantic processing) is primarily dependent upon the left temporal neocortex ${ }^{26}$, whereas the right hemisphere complements and enriches the left hemisphere' work ${ }^{5}$. This perspective ${ }^{5}$ is in line with previous evidence provided by Mummery et al. ${ }^{27}$ who reported that the left anterior temporal lobe and the anterior cingulate activations observed in their PET study co-varied with the proportion of related pairs in the experiment.

In another fMRI study, in a semantic priming paradigm, O'Hare, Dien, Watersona and Savageb ${ }^{24}$ employed a visual lexical decision task with an SOA of $500 \mathrm{~ms}$ with a group of 17 participants. The authors found a significant activation in the right posterior cingulated, with related prime pairs as compared to unrelated prime pairs. This data replicated a previous event-related potentials (ERP) study ${ }^{28}$ which observed a word N300 in a word similar experiment.

Wible et al. ${ }^{29}$, using a long SOA $(750 \mathrm{~ms})$ and an oral lexical decision task with related word pairs varying in their degree of connectivity - number of connections among associates 
divided by the number of associates - reported reduced cortical activation for related word pairs of high connectivity, followed by related word pairs of low connectivity. Besides, the significant and bilateral activations observed in the posterior, superior and middle temporal regions declined as the semantic priming of the word pairs increased. This may express complexity issues once fMRI studies on lexical learning show that more activation is associated to effortful processing, as opposed to more automatic processing, which results in less activation ${ }^{30}$.

Regarding automatic semantic priming effects (SOA of $200 \mathrm{~ms}$ ), Sachs et al. ${ }^{25}$ examined 16 healthy males with a visual semantic priming task, including taxonomic (i.e. classification) and thematic (context) relations. Significant signal changes associated to the taxonomic priming effect were observed in the right precuneus, the postcentral gyrus and the middle frontal and superior frontal gyri; thematic priming effects resulted in significant activations in the rightmiddle frontal gyrus and the anterior cingulate. Also examining automatic semantic priming effects, Liu, Hub, Peng, Yang and $\mathrm{Li}^{31}$ tested a $50 \mathrm{~ms}$ SOA in a visual lexical decision task. They compared conceptual and affective priming, and found involvement of the left-middle/superior temporal gyrus, frontal gyrus and right superior temporal gyrus involved in both types of priming. However, some areas were conceptual specific, such as left inferior frontal gyrus and right superior temporal gyrus. These results ${ }^{31,25}$ demonstrate that, despite comparable behavioral effects (between taxonomic and thematic relations, and between conceptual and affective priming), there are both neural dissociation and shared neural bases working on these processes ${ }^{32}$.

Examined the patterns of neural activation during a semantic judgment task and a lexical decision task within a semantic priming paradigm, the former required explicit semantic analysis, whereas the latter required implicit semantic processing. Although both tasks significantly activated the left inferior frontal gyrus, activation maps were larger and included the superior temporal gyrus only with the semantic activation task. The authors argued that the greater activation observed in the semantic judgment task reflected the deeper semantic processing of semantic judgment, as compared to lexical decisions. Thus, this study showed that the recruitment of the left frontal areas, as well as the posterior areas, during lexical semantic tasks is modulated by the type of semantic processing induced by the task.

In Sass et al. ${ }^{33}$ study, they assessed the semantic priming effect during an event-related fMRI lexical decision task (visual and auditory) with related and unrelated primes in a group of healthy adults. The prime duration was approximately $355 \mathrm{~ms}$. The authors showed significant left frontal and temporal parietal activations. Moreover, an increase in the BOLD response was observed in all the main clusters of activation with the related prime condition, as compared to those with the non-related condition. These data suggest once again that part of the semantic priming effect involves retrieval of semantic and/or episodic information ${ }^{33}$.

Henson $^{34}$ reviewed the PET and fMRI studies of priming in humans within specific paradigms (as word-stem completion and visual object priming). Referring specifically to semantic priming studies, he summarizes that imaging studies are starting to use priming as a tool to investigate language systems, at least at the level of lexical-semantics. The semantic priming effect has been related to inferior and superior temporal lobe processing ${ }^{35}$, to the left pre-frontal cortex ${ }^{36,37}$ and to the left inferior frontal gyrus and the left medial and left inferior temporal gyri ${ }^{38}$. Determining the neurological basis of semantic priming is difficult, mainly because it arises from complex processes ${ }^{39}$.

In summary, there is evidence that semantic priming effects are related to an extensive network which includes the temporal lobe, the pre-frontal cortex, the left frontal gyrus, the left temporal gyrus and the cingulated cortex. The neuroimaging evidence on the semantic priming effect is not convergent regarding the activation pattern. Thus, some authors reported reduced activations under the related condition ${ }^{29,40}$, whereas other authors report the opposite pattern ${ }^{24,33,41,42}$. Also, the literature reports increased cortical activity ("response enhancement") at the same related condition, as well as the opposite pattern. Still, the most common finding in functional imaging studies on semantic priming effects is a reduced response for primed versus unprimed stimuli, called "repetition suppression" ${ }^{4}$.

\section{STUDIES CONCERNING SEMANTIC PRIMING IN APHASIC PATIENTS}

The literature on semantic priming effects in aphasic patients is controversial. Researchers do not agree on whether priming effects can be preserved in patients with language comprehension deficits (such as in Wernicke's aphasia) or whether they are impaired in cases of a relative preservation of language comprehension, as in Broca's or non-fluent apha$\operatorname{sias}^{43-45}$. There are studies which show that patients with both comprehensive (fluent) and expressive (non-fluent) language deficits are able to use the semantic knowledge in implicit (indirect) tasks, even if they are not able to use it in an explicit way ${ }^{44,46}$ such as naming tasks. Nevertheless, Baum ${ }^{47}$ shows that, despite non-fluent aphasic patients present patterns similar to the controls in terms of semantic priming, only $50 \%$ of them (the ones with less serious deficits in semantic processing) showed the semantic priming effect. On the other hand, they were found semantic priming effects only in fluent aphasics ${ }^{44,45}$.

Other studies cited below found different semantic priming patterns, depending upon the aphasia profile. These differences have been attributed to the methodological and 
participant selection issues and other experimental variables $^{48}$. Tables 1 and 2 summarize the findings of some of the studies presented in this section.

Milberg and Blumstein ${ }^{44}$ studying two clinical groups fluent and non-fluent aphasias - compared to a control group, found the performance of Wernicke's aphasics similar to controls, but found no priming effect in Broca's aphasics. Milberg, Blumstein and Dworetzky ${ }^{45}$ concluded that Wernicke's aphasics are more capable of dealing with lexicalsemantic processing than may be expected given their ability to make semantic judgment, to understand names of objects and to understand language in general. In contrast, Broca's aphasics did not demonstrate semantic facilitation in any priming situation, suggesting that their deficits are related to automatic access to lexical representations of words ${ }^{45}$. It is noteworthy that Milberg and Blumstein ${ }^{44}$ used an SOA of $2000 \mathrm{~ms}$ and that Milberg et al. ${ }^{45}$ tested with an SOA of 500 ms. Nowadays, it is known that these SOAs can activate controlled processes as well ${ }^{21}$. Additionally, each of the clinical samples in these studies was small $(n=6)$ and heterogeneous.

Later, using an actually short SOA (250 ms), Del Toro ${ }^{43}$ didn't find semantic priming effect. He examined a group of participants with Broca's aphasia and assessed lexical decision abilities with a semantic priming paradigm. The author ${ }^{43}$ reported faster (lower RT) and more accurate responses for the neutral prime condition (baseline) as compared to the other two conditions in that the primes were words related or unrelated to target, which indicates that context has an inhibiting effect. The global semantic priming effect was absent, as shown by the lack of difference between response times for unrelated and related word pairs. These results lead the author to conclude that participants with Broca's aphasia have impaired automatic lexical access ${ }^{43}$. It is, however, important to stress that this study used a small group of participants, and thus the lack of semantic priming effect may have resulted from poor statistical power.

On the other hand, the results of the study by Milberg et al. ${ }^{49}$ showed that participants with Broca's aphasia are, in part, similar to the controls and different from those with Wernicke's aphasia in terms of semantic priming. They used experiments with an inter-stimulus-interval (ISI) of 200 and $600 \mathrm{~ms}$ (automatic and controlled processes, respectively). The authors argued that in Broca's aphasia the pattern for short SOAs may reflect a reduction in the flexibility and the speed of access to lexical information, which may contribute to difficulty in producing fluent speech. In contrast, the pattern found in Wernicke's aphasia suggests a lesser ability to use context to interpret words. Prather, Zurif, Stern and Rosen $^{50}$ and Grindrod and Baum ${ }^{51}$ agree that there is slower access to lexical information in non-fluent (Broca's) aphasias. In a case study with list priming paradigm (LPP), Prather et al. ${ }^{50}$ used an ISI ranging from 500 to $1800 \mathrm{~ms}$. The non-fluent aphasic patient showed a semantic priming effect only at a delay of $1.500 \mathrm{~ms}$, which is consistent with the theory of controlled process effects. Grindrod and Baum ${ }^{51}$ evaluated left-hemisphere-damaged (LHD) non-fluent aphasic, righthemisphere-damaged (RHD) and non-brain-damaged (NBD) control subjects with a cross-modal semantic priming task. The aim of this study was to investigate the ability to use a discourse context to resolve lexically ambiguous words.

Furthermore, in studying non-fluent aphasias, Mimura, Goodglass and Milberg ${ }^{52}$ assessed a patient with alexia who exhibited serious deficits in the semantic combination of words and figures in an SOA of $500 \mathrm{~ms}$ with visual stimuli. In spite of that, the patient showed the semantic priming effect, responding more quickly and accurately to words preceded by primes semantically related. The study suggests that, even in severe cases of alexia, implicit access to semantic information may be preserved. Both designed single-case studies ${ }^{50,52}$.

In order to investigate reasons for comprehension deficits in Broca's aphasic subjects, Myers and Blumstein ${ }^{53}$ designed three experiments. Only the first study evaluated semantic priming effects, comparing the aphasics with normal subjects. Auditory stimuli were presented with an ISI of 250 ms. Results once again showed a similar pattern of semantic priming effect between groups with both reacting faster for the semantic related condition than for the unrelated one. The same results were found in Utman, Blumstein and Sullivan $^{54}$ study. They used a lexical decision task with auditory stimuli and ISIs of $50 \mathrm{~ms}$ and $250 \mathrm{~ms}$. Broca's aphasics and normal subjects showed semantic priming effect with both ISIs. In another study, using visual stimuli and SOAs ranging from 300 to 3100 ms, Prather, Zurif, Love and Brownell ${ }^{48}$ assessed a patient with Broca's aphasia who showed the priming effect with an SOA of $1500 \mathrm{~ms}$ - he was capable of accessing the lexical information as long as he had time for such processing. This result is the same as in the previous study ${ }^{50}$. On the other hand, the participant with Wernicke's aphasia exhibited priming effect with all SOAs (from 300 to $1100 \mathrm{~ms}$ ), reflecting deficits in the ability to inhibit lexical activation.

Howard, Hickin, Redmond, Clark and Best ${ }^{55}$ divided the group of aphasics according to the extent of their semantic deficits. The task used was the word-figure combination and later naming of the target. The effect of semantic (contextual) facilitation was broader and longer-lasting for cases with fewer semantic deficits. Aphasics with semantic deficits showed significant facilitation only with a short stimulus onset asynchrony, while cases with less severe semantic deficits showed facilitation for both long and short stimulus onset asynchronies.

Hagoort ${ }^{56}$ found that patients with Broca's aphasia displayed normal semantic priming effects (in a lexical decision task) with SOAs of $1400 \mathrm{~ms}$ and $300 \mathrm{~ms}$, a pattern similar to controls. Thus, the author questioned the hypothesis that suggests deficient automatic access to lexical-semantic information in Broca's aphasia. The evidence is more compatible with the hypothesis which holds that Broca's aphasia is 


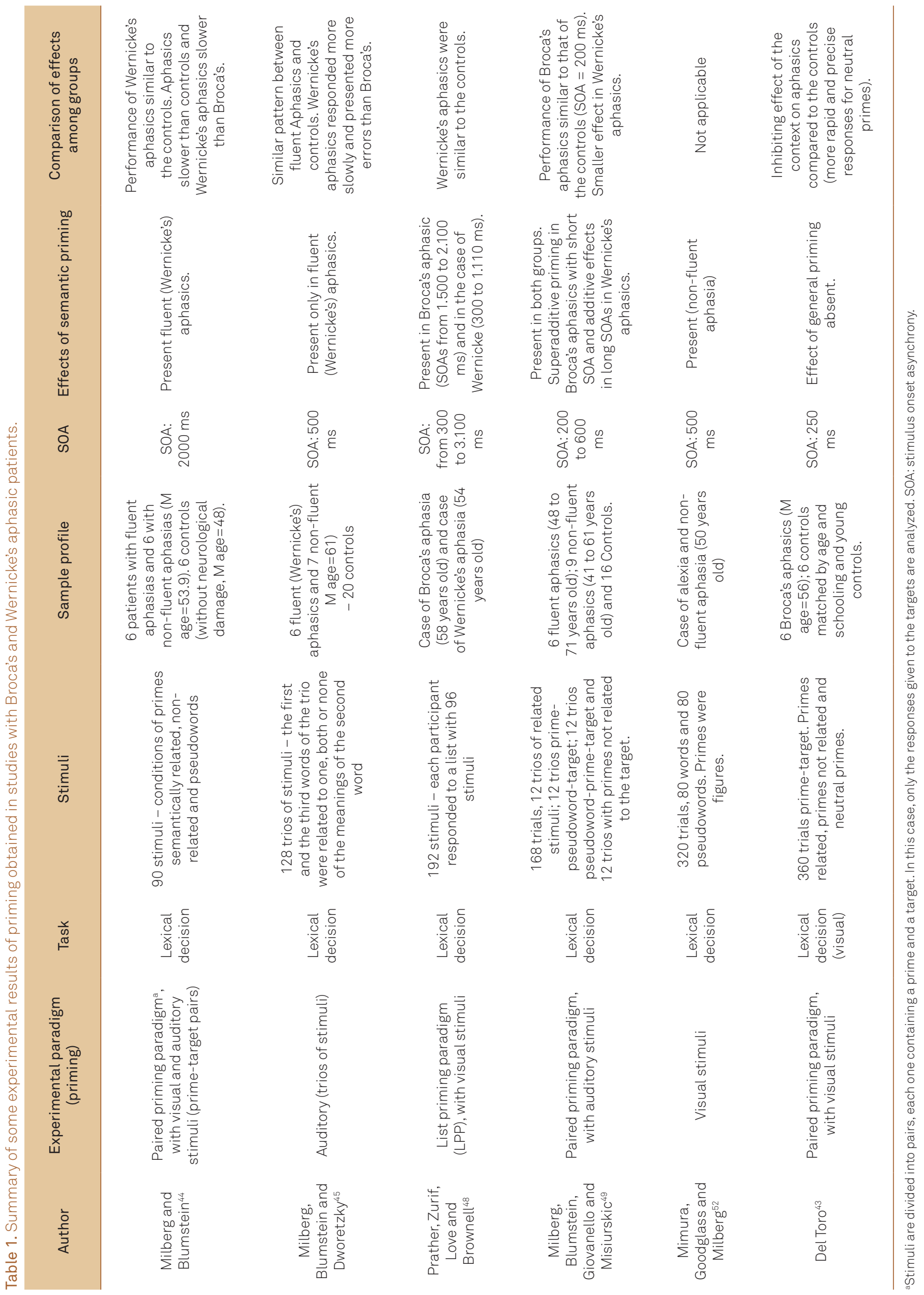


Table 2. Studies that found preservation of semantic priming effects on aphasic patients, according to the type of aphasia (fluent and non-fluent).

\begin{tabular}{|c|c|c|}
\hline Author & Fluent aphasias & $\begin{array}{l}\text { Non-fluent } \\
\text { aphasias }\end{array}$ \\
\hline $\begin{array}{l}\text { Milberg and } \\
\text { Blumstein }{ }^{44}\end{array}$ & $x$ & \\
\hline Milberg et al. ${ }^{45}$ & $x$ & \\
\hline $\begin{array}{l}\text { Mimura, Goodglass } \\
\text { and Milberg }\end{array}$ & Does not apply & $x$ \\
\hline Baum ${ }^{47}$ & & $x$ \\
\hline Prather et al. ${ }^{48}$ & $x$ & $x$ \\
\hline Milberg et al. ${ }^{49}$ & $x$ & $x$ \\
\hline Hagoort ${ }^{56}$ & & $x$ \\
\hline Del Toro 43 & $\begin{array}{l}\text { Inhibiting effect of the } \\
\text { context (faster and more } \\
\text { precise responses to } \\
\text { neutral prime) }\end{array}$ & $x$ \\
\hline $\begin{array}{l}\text { Myers and } \\
\text { Blumstein }\end{array}$ & $x$ & $x$ \\
\hline
\end{tabular}

characterized by deficits in the post-lexical integration processes of the meaning of words. The author ${ }^{56}$ highlighted another point that challenges the automatic access hypothesis in Broca's aphasia, and argued that this point of view implicitly conveys the idea that studies on the semantic priming of words extract only or predominantly automatic processing of the lexical information, including the meaning of the word. In fact, the author ${ }^{56}$ argued that semantic priming effects may result from both automatic processing and a controlled mechanism, and thus the integrity of lexical-semantic representations is not guaranteed by the mere presence of automatic semantic priming effects ${ }^{8}$.

To summarize, aphasia is characterized by dissociation between linguistic knowledge representation and the access to such representations ${ }^{49}$. This dissociation is the source of a variety of communication deficits. Therefore, those who have aphasias with predominant comprehension-based deficits are more likely to demonstrate low performance in tasks requiring explicit semantic, syntactic or phonological processing. However, they generally exhibit better performance in semantic implicit tasks (like those in the semantic priming paradigm). In contrast, predominantly expressive aphasias are characterized by preserved explicit semantic judgment ${ }^{49}$, but the literature is not convergent about the implicit semantic processing and, thus, further studies are necessary.

\section{FINAL REMARKS}

Some of the reviewed studies showed evidence of the semantic priming effects presence in both fluent and nonfluent aphasias. Still, the evidence is not convergent, and thus more studies are necessary. A series of factors could be interfering in this diversity of findings, for example: the experimental paradigm of priming (paired priming paradigm or LPP), the stimulus selection criteria and presentation modality (visual or auditory), the type of stimulus (words or figures), the number of trial in the experiment, the base line or control condition in the experiment (presence of neutral primes), the sample selection criteria, the sample heterogeneity and small clinical groups, the presence of a control group, the SOA or ISI used in the priming experiment (controlled or automatic semantic processes), etc.

The type of priming paradigm may explain performance differences in behavioral studies ${ }^{48}$ and in neuroimaging studies $^{23,24,29,40-42}$. Regarding studies on clinical populations, the challenge is even bigger, given the variability across patients and the numerous factors that may prevent rigorous methodological control and lead to inconsistent findings, including age $e^{44}$, lesion type, location and extension. It should be noted that many studies of semantic priming effects in Broca's aphasia have been carried out with auditory stimuli. Also, caution is necessary when interpreting single-case data; the generalization of such findings to one aphasia type should be avoided.

From a clinical aphasiology perspective, it could be noted that, given the complexity of the language-communication function, a global cognitive picture of the aphasic person should be considered ${ }^{57}$. Thus, assessment with a semantic priming paradigm may contribute to establish a more complete profile of the patient's neuropsychological status and provide relevant information to guide therapy choices in terms of priming effects facilitation in different therapy contexts, which in turn may contribute to improve language, communication abilities ${ }^{20}$. This information may be used to develop intervention programs and strategies, serving as basis for minimizing deficits. Also, considering the impact of short versus long SOAs on priming effects may provide cues regarding the processing time required to attain optimal performance in each specific aphasia case.

Priming is one of the most basic expressions of human memory, influencing how we perceive and interpret the world ${ }^{34}$. Therefore, by examining the relative preservation or impairment of implicit and explicit access to lexical-semantic knowledge, it is possible to determine to what extent either of them can be used to assist in effective communication of people with aphasia and their proxies. So, on-line studies of semantic priming have been widely used to investigate the nature of the semantic memory deficits in aphasias. This knowledge can be further used to orient therapy on the disturbed and preserved dimensions of semantic priming effects basis. We hope this review helps the researcher and clinical professional to plan their assessment battery and the rehabilitation procedures. The possible dissociation between direct and indirect measures of lexical-semantic processes is an important data for these planning. 


\section{References}

1. Hillis AE. Aphasia: progress in the last quarter of a century. Neurology. 2007;69:200-213.

2. Benson DF, Ardila A. Aphasia: a clinical perspective. New York: Oxford University Press; 1996.

3. Ardila A. A proposed reinterpretation and reclassification of aphasic syndromes. Aphasiology 2010;24:363-394.

4. Baumgaertner A, Tompkins CA. Testing contrasting accounts of word meaning activation in Broca's aphasia: experiences from a crossmodal semantic priming study. Aphasiology 2002;16:397-411.

5. Kahlaoui K, Joanette Y. Normal and pathological semantic processing of words. In: Ball M, Perkins M, Müller N, Howard S (eds). The handbook of clinical linguistics. Oxford, UK: Blackwell Publishing; 2008.

6. Raymer AM, Rothi LJG. Cognitive approaches to impairments of word comprehension and production. In: Chapey R (ed). Language intervention strategies in aphasia and related neurogenic communication disorders. 4. ed. Philadelphia: Lippincott Williams \& Wilkins; 2001:524-550.

7. Carmona MB, González JMI, Gómez AR. Psicología del lenguage. Investigación y teoría. Madrid: Editorial Trotta; 1992.

8. Hagoort P. The shadows of lexical meaning in patients with semantic impairments. In: Stemmer B, Whitaker HA (Eds). Handbook of neurolinguistics. New York: Academic Press; 1998.

9. Plaut DC, McClelland JL, Seidenberg MS, Patterson K. Understanding normal and impaired word reading: computational principles in quasi-regular domains. Psychol Rev 1996;103:56-115.

10. Seidenberg MS, McClelland JL. A distributed, developmental model of word recognition and naming. Psychol Rev 1989;96:523-568.

11. Hillis AE. The organization of the lexical system. In: Rapp B (Ed). What deficits reveal about the human mind/brain: a handbook of cognitive neuropsychology. Philadelphia: Psychology Press; 2001:185-201.

12. Rapp B, Goldrick M. Speaking words: contribution of cognitive neuropsychological research. Cogn Neuropsychol 2006;23:39-73.

13. Miller G. On knowing a word. Annu Rev Psychol 1999;50:1-19.

14. McClelland JL, Rogers TT. The parallel distributed processing approach to semantic cognition. Nat Rev Neurosci 2003;4:310-322.

15. NeelyJH.Semantic priming effects in visual word recognition:a selective review of current findings and theories. In: Besner D, Humphreys GW (eds). Basic processes in reading, visual word recognition. New Jersey: Lawrence Erlbaum Associates; 1991:264-336.

16. Del Vecchio N, Liporace J, Nei M, Sperling M, Tracy J. A dissociation between implicit and explicit verbal memory in left temporal lobe epilepsy. Epilepsia 2004:1124-1133.

17. Strauss E, Sherman EMS, Spreen O. A compendium of neuropsychological tests: administration, norms and commentary. 3rd ed. New York: Oxford University Press; 2006.

18. Fonseca RP, Salles JF, Parente MAMP. Ferramenta útil na pesquisa e clínica de neuropsicologia: um compêndio de testes neuropsicológicos. Rev Interamer Psicol 2007;41:403-406.

19. Bolognani SA, Gouveia PA, Brucki SM, Bueno OF. Memória implícita e sua contribuição à reabilitação de um paciente amnéstico. Arq Neuropsquiatr 2000;58:924-930.

20. Renvall K, Laine M, Martin N. Treatment of anomia with contextual priming: Exploration of a modified procedure with additional semantic and phonological tasks. Aphasiology 2007;21:499-527.

21. McNamara TP. Semantic priming: perspectives from memory and word recognition. New York, USA: Routledge; 2005.

22. Altarriba J, Basnight-Brown DM. Methodological considerations in performing semantic - and translation - priming experiments across languages. Behav Res Methods 2007;39:1-18.

23. Hauk O, Davis MH, Kherif F, Pulvermüller F. Imagery or meaning? Evidence for a semantic origin of category-specific brain activity in metabolic imaging. Eur J Neurosci 2008;27:1856-1866.
24. O'Hare AJ, Dien J, Waterson LD, Savageb CR. Activation of the posterior cingulate by semantic priming: a co-registered ERP/fMRI study. Brain Res 2008;1189:97-114

25. Sachs O, Weis S, Zellagui N, et al. Automatic processing of semantic relations in fMRI: neural activation during semantic priming of taxonomic and thematic categories. Brain Res 2008;1218:194-205.

26. Cappa SF, Perani D. The neural correlates of noun and verb processing. J Neurolinguistics 2003;16:183-189.

27. Mummery C, Shallice T, Price CJ. Dual-process model in semantic priming: a functional imaging perspective. Neuroimage 1999;9:516-525.

28. Franklin MS, Dien J, Neely JH, Waterson LD, Huber L. Semantic priming modulates the N400, N300, and N400RP. Clin Neurophysiol 2007;118:1053-1068.

29. Wible CG, Han SD, Spencer MH, et al. Connectivity among semantic associates: an fMRI study of semantic priming. Brain Lang 2006;97:294-305

30. Raboyeau G, Marcotte K, Adrover-Roig D, Ansaldo Al. Brain activation and lexical learning: the impact of learning phase and word type. Neuroimage 2010;49:2850-2861.

31. Liu H, Hub Z, Peng D, Yang Y, Li K. Common and segregated neural substrates for automatic conceptual and affective priming as revealed by event-related functional magnetic resonance imaging. Brain Lang 2010;112:121-128.

32. Ruff I, Blumstein SE, Myers EB, Hutchison E. Recruitment of anterior and posterior structures in lexical-semantic processing: an fMRI study comparing implicit and explicit tasks. Brain Lang 2008;105:41-49.

33. Sass K, Krach S, Sachs O, Kircher T. Lion - tiger - stripes: neural correlates of indirect semantic priming across processing modalities. Neuroimage 2009;45:224-236.

34. Henson RNA. Neuroimaging studies of priming. Progr Neurobio 2003;70:53-81.

35. Verfaellie M, Keane MM. The neural basis of aware and unaware forms of memory. Semin Neurol 1997;17:153-161.

36. Raichle M, Fiez JA, Videen TO. Practice-related changes in human brain functional anatomy during nonmotor learning. Cereb Cortex 1994;4:8-26.

37. Demb J, Desmond J, Wagner A, Vaidya CJ, Glover GH, Gabrieli JD. Semantic encoding and retrieval in the left inferior prefrontal cortex: a functional MRI study of task difficulty and process specificity. J Neurosci 1995;15:5870-5878.

38. Blaxton T. Cognition: memory, 2: conceptual and perceptual memory. Amer J Psychiatry 1999;156:1676.

39. Kahlaoui K, Ska B, Degroot C, Joanette Y. Neurobiological bases of the semantic processing of words. In: Guendozi J, Loncke F, Williams MJ (Eds). The handbook of psycholinguistic and cognitive processes: perspectives in communication disorders. LEA: Taylor \& Francis; 2008.

40. RissmanJ,EliassenJC,Blumstein SE.Anevent-related FMRI investigation of implicit semantic priming.J Cogn Neurosci 2003;15:1160-1175.

41. Kotz SA, Cappa SF, von Cramon DY, Friederici AD. Modulation of the lexical-semantic network by auditory semantic priming: an eventrelated functional MRI study. Neuroimage 2002;17:1761-1772.

42. Raposo A, Moss HE, Stamatakis EA, Tyler LK. Repetition suppression and semantic enhancement: an investigation of the neural correlates of priming. Neuropsychologia 2006;44:2284-2295.

43. Del Toro JF. An examination of automatic versus strategic semantic priming effects in Broca's aphasia. Aphasiology 2000;14:925-947.

44. Milberg W, Blumstein SE. Lexical decision and aphasia: evidence for semantic processing. Brain Lang 1981;14:371-385.

45. Milberg W, Blumstein SE, Dworetzky B. Processing of lexical ambiguities in aphasia. Brain Lang 1987;31:138-150.

46. Bondi MW, KaszniakAW, Rapcsak SZ, Butters MA. Implicit and explicit memory following communicating anterior artery aneurysm rupture. Brain Cogn 1993;22:213-229. 
47. Baum SR. Phonological, semantic, and mediated priming in aphasia. Brain Lang 1997;60:347-359.

48. Prather PA, Zurif E, Love T, Brownell H. Speed of lexical activation in nonfluent Broca's aphasia and fluent Wernicke's aphasia. Brain Lang 1997;59:391-411.

49. Milberg W, Blumstein S, Giovanello KS, Misiurski C. Summation priming in aphasia: evidence for alterations in semantic integration and activation. Brain Cogn 2003;51:31-47.

50. Prather P, Zurif E, Stern C, Rosen TJ. Slowed lexical access in nonfluent aphasia: a case study. Brain Lang 1992;43:336-348.

51. Grindrod CM, Baum SR. Hemispheric contributions to lexical ambiguity resolution in a discourse context: evidence from individuals with unilateral left and right hemisphere lesions. Brain Cogn 2005;57:70-83.
52. Mimura M, Goodglass $H$, Milberg W. Preserved semantic priming effect in alexia. Brain Lang 1996;54:434-446.

53. Myers EB, Blumstein SE. Selectional restriction and semantic priming effects in normals and Broca's aphasics. J Neurolinguistics 2005;18:277-296.

54. Utman JA, Blumstein SE, Sullivan K. Mapping from sound to meaning: reduced lexical activation in Broca's aphasics. Brain Lang 2001;79:444-472.

55. Howard D, Hickin J, Redmond T, Clark P, Best W. Re-visiting "semantic facilitation" of word retrieval for people with aphasia: facilitation yes but semantic no. Cortex 2006;42:946-962.

56. Hagoort P. Semantic priming in Broca's Aphasics at a Short SOA: no support for an automatic access deficit. Brain Lang 1997;56:287-300.

57. Helm-Estabrooks N. Cognition and aphasia: a discussion and study.J Comunic Disord 2002;35:171-186. 